\title{
PRINCIPALES TRATADOS EN MATERIA DE PROPIEDAD INDUSTRIAL ADMINISTRADOS POR LA OMPI*
}

\author{
Oficina InTERnacional De La OMPI
}

\section{Introducción}

La Organización Mundial de la Propiedad Intelectual -en forma abreviada, OMPI-, fue establecida en virtud de un convenio firmado en Estocolmo, Suecia, el 14 de julio de 1967 y titulado «Convenio que establece la Organización Mundial de la Propiedad Intelectual». Este convenio entró en vigor en 1970 y a la fecha cuenta con 134 Estados miembros!.

El origen de la OMPI, tal como se conoce hoy ${ }^{2}$, se remonta a los años 1883 y 1886, durante los que se adoptaron el Convenio de París para la Protección de la Propiedad Industrial y el Convenio de Berna para la Protección de las Obras Literarias y Artísticas, respectivamente. Cada uno de estos convenios establecía la creación de una secretaría, llamada «Oficina Internacional». Las dos secretarías fueron reunidas en 1893 y recibieron diversos nombres, el último de los cuales fue el de Oficinas Internacionales

* Artículo preparado por la Oficina Internacional de la Organización Mundial de la Propiedad Intelectual (OMPI).

1 La República del Perú es miembro de la OMPI desde el 4 de septiembre de 1980.

2 Para una reseña histórica y un detallado análisis de las actividades de la OMPI, ver: Bogsch, Arpad, «Brief History of the First 25 Years of the World Intellectual Property Organization», en: The First Twenty Five Years of the World Intellectual Property Organization, 1967 - 1992, pp. 15-90; Ginebra, International Bureau of Intellectual Property, 1992. Dicha publicación también contiene un recuento de las actividades desarrolladas por la OMPI durante ese período. 
Reunidas para la Protección de la Propiedad Intelectual, también conocidas como «BIRPI» (sigla de este nombre en francés).

La OMPI adquirió el estatuto de organismo especializado de las Naciones Unidas en diciembre de $1974^{3}$.

La OMPI tiene dos objetivos principales ${ }^{4}$. El primero consiste en el fomento de la protección de la propiedad intelectual en todo el mundo mediante la cooperación entre los Estados y, en su caso, con la colaboración de cualquier otra organización internacional. El segundo objetivo es asegurar la cooperación administrativa entre las Uniones de Propiedad Intelectual ${ }^{5}$.

En relación con el primer objetivo, esto es, el fomento de la protección de la propiedad intelectual en todo el mundo ${ }^{6}$, la OMPI favorece la conclusión de nuevos tratados internacionales y la modernización de las legislaciones nacionales; presta asistencia técnica a los países en desarrollo; reúne y difunde información sobre propiedad intelectual; mantiene servicios destinados a facilitar la obtención de protección para las invenciones, marcas y dibujos y modelos industriales cuando se desea obtenerla en varios países; y promueve la cooperación administrativa entre los Estados miembros $^{7}$. En lo referido al segundo objetivo, esto es, la cooperación administra-

3 Acuerdo entre las Naciones Unidas y la OMPI, adoptado por la Asamblea General de las Naciones Unidas el 17 de diciembre de 1974 y aprobado por la Asamblea General de la OMPI el 27 de septiembre de 1974. Entró en vigor el 17 de diciembre de 1974, tal como quedó refrendado en el protocolo suscrito por el Secretario General de las Naciones Unidas y el Director General de la OMPI el 21 de enero de 1975.

4 Consagrados en el artículo 3 del Convenio que establece la Organización Mundial de la Propiedad Intelectual.

5 Las Uniones son personas jurídicas de derecho público internacional constituidas por los tratados que administra la OMPI. Así, por ejemplo, el Convenio de París para la Protección de la Propiedad Industrial crea la «Unión de París», constituida por el conjunto de los Estados parte en ese convenio.

6 La propiedad intelectual comprende dos ramas principales: la propiedad industrial (que protege principalmente las invenciones, las marcas y los diseños industriales), y el derecho de autor (que protege principalmente las obras literarias, musicales, artísticas, fotográficas y audiovisuales). El presente artículo está referido exclusivamente a la primera de las ramas indicadas anteriormente.

7 Para un resumen de las actividades desarrolladas por la OMPI en el Perú en 
tiva entre las Uniones, la OMPI centraliza la administración de las Uniones en la Oficina Internacional de Ginebra, Suiza, que es la Secretaría de la OMPI, y supervisa esa administración por medio de diversos órganos. Cabe destacar que la centralización proporciona ventajas económicas a los Estados miembros y al sector privado interesado en la propiedad intelectual ${ }^{8}$. Del mismo modo la OMPI tiene como objetivo asegurar la cooperación administrativa entre las Uniones de propiedad intelectual y proporciona servicios administrativos y financieros a la Unión Internacional para la Protección Internacional de las Obtenciones Vegetales (UPOV).

Adicionalmente la OMPI, en su calidad de organismo especializado de las Naciones Unidas, es responsable de la adopción de las medidas apropiadas, de acuerdo con su instrumento básico, así como con los tratados y acuerdos que administra, para promover, entre otras cosas, la actividad intelectual creadora y facilitar la transferencia a los países en desarrollo de la tecnología relativa a la propiedad industrial con el fin de acelerar su desarrollo económico, social y cultural, con sujeción a la competencia de las Naciones Unidas y sus órganos, así como de otros organismos del sistema de las Naciones Unidas ${ }^{10}$.

En lo que respecta a las actividades en beneficio de los países en desarrollo, la OMPI planifica y ejerce sus actividades de cooperación internacional para el desarrollo, procurando, en particular, un máximo de aprovechamiento de la propiedad intelectual para el estímulo de las actividades creadoras nacionales, para la adquisición de tecnología extranjera y de obras

consonancia con este objetivo, ver: Bogsch, Arpad, op. cit., Country Profile: Perú; pp. 418-19.

8 Es del caso mencionar que la centralización no es completa en cuanto al derecho de autor y a los derechos conexos, ya que la administración de la Convención de Roma, que se ocupa de los derechos conexos, se comparte con la UNESCO y con la Oficina Internacional del Trabajo (OIT).

9 La UPOV fue establecida en el Convenio Internacional para la Protección de las Obtenciones Vegetales, del 2 de diciembre de 1961, enmendado el 10 de noviembre de 1972, y revisado el 23 de octubre de 1978 y el 19 de marzo de 1991. De conformidad con el artículo 4 del Acuerdo suscrito entre la OMPI y la UPOV, el Director General de la OMPI es el Secretario General de la UPOV.

${ }^{10}$ Conforme al artículo 1 de su Acuerdo con las Naciones Unidas. Ver supra nota 3 . 
literarias y artísticas de origen extranjero, y para facilitar el acceso a la información científica y tecnológica contenida en los documentos de patente. Todo esto debe servir a los fines del desarrollo cultural, económico y social de los países en desarrollo"

A continuación se reseña el contenido de los principales tratados que, en materia de propiedad industrial, administra la OMPI. Es del caso resaltar que el primero de ellos, el Convenio de París para la Protección de la Propiedad Industrial, es el tratado marco de los restantes, siendo requisito para acceder a éstos, ser parte de aquél. Además de los tratados que se comentan en el presente artículo, la OMPI también administra los siguiente tratados, en materia de propiedad industrial: el Arreglo de Niza, de 15 de junio de 1957, relativo a la Clasificación Internacional de Productos y Servicios para el Registro de Marcas; el Arreglo de Locarno, de 8 de octubre de 1968, que establece una Clasificación Internacional de Dibujos y Modelos Industriales; el Arreglo de Estrasburgo relativo a la Clasificación Internacional de Patentes, de 24 de marzo de 1971; el Acuerdo de Viena, de 12 de junio de 1973, por el que se establece una Clasificación Internacional de elementos figurativos de marcas; el Tratado de Budapest, de 28 de abril de 1977, sobre el Reconocimiento Internacional del Depósito de Microorganismos a los fines de procedimiento en materia de patentes; el Tratado de Nairobi, de 26 de septiembre de 1982, sobre la Protección del Símbolo Olímpico; y el Tratado de Washington, de 26 de mayo de 1989, sobre la Propiedad Intelectual respecto de los Circuitos Integrados (este último aún no ha entrado en vigor).

\section{Convenio de París para la Protección de la Propie- dad Industrial}

Aspectos generales:

El Convenio de París para la Protección de la Propiedad Industrial (en ade-

11 Así. para el detalle de sus actividades de cooperación, la OMPI publica anualmente un documento contentivo de las mismas. Para el caso de las desarrolladas en el Perú durante 1991, ver: «Informe de las actividades de cooperación para el desarrollo llevadas a cabo por la OMPI para los países de América Latina y el Caribe y las áreas de propiedad industrial y derecho de autor durante 1991»; Documento WO/INF/89, julio 1992. 
lante, el Convenio de París) fue firmado en París, el 20 de marzo de 1883. Después de su entrada en vigor, el Convenio fue revisado en seis ocasiones ${ }^{12}$. El Acta de Estocolomo es la versión más reciente del Convenio de París y es la que se aplica a la mayoría de sus Estados partes. El Convenio de París cuenta actualmente con 107 Estados partes ${ }^{13}$.

El Convenio de París contiene 27 artículos que tratan cuestiones de derecho sustantivo y pueden agruparse bajo tres categorías diferentes, en cuanto a los efectos que ellas tienen con respecto a la legislación nacional de sus países miembros. Un primer grupo está constituido por aquellas disposiciones que obligan o que permiten a los Estados partes legislar en relación con determinados aspectos del derecho de la propiedad industrial. Una segunda categoría de normas está constituida por aquellas que regulan los derechos y las obligaciones de personas de derecho privado al exigir o requerir que la legislación nacional de los Estados miembros se aplique a tales personas. Una tercera categoría se refiere a las que regulan derechos y obligaciones de personas de derecho privado que serían aplicables directamente a la situación considerada. En cualquier caso conviene resaltar que el Convenio de París deja gran libertad a los Estados para legislar en los aspectos sustantivos y procesales relativos a la protección e inscripción de los derechos de propiedad industrial.

Entre las disposiciones contenidas en el Convenio de París merecen destacarse las siguientes:

\section{Constitución de una Unión; ámbito de la propiedad indus- trial [artículo 1]}

Los Estados contratantes del Convenio de París constituyen una «Unión» para la protección de la propiedad industrial. Esta Unión, conocida como la

${ }^{12}$ Las revisiones son las siguientes: Bruselas el 14 de diciembre de 1900; Washington el 2 de junio de 1911; La Haya el 6 de noviembre de 1925; Londres el 2 de junio de 1934; Lisboa el 31 de octubre de 1958; y Estocolmo el 14 de julio de 1967. Adicionalmente fue enmendado el 28 de septiembre de 1979.

${ }^{13}$ Entre los Estados partes se encuentran los siguientes de América Latina: Argentina, Brasil, Cuba, Chile, México, República Dominicana y Uruguay. El Perú todavía no es Estado miembro. 
Unión de París, es una persona jurídica de derecho público internacional. Tiene sus propios órganos rectores, a saber, la Asamblea de la Unión, el Comité Ejecutivo y la Oficina Internacional de la OMPI dirigida por su Director General. La Unión de París financia sús actividades a través de las contribuciones de los Estados miembros, que se plasman en un programa y presupuesto bienal aprobado por la Asamblea de la Unión.

El artículo 1 define el ámbito de aplicación del Convenio. El primer párrafo de este artículo señala que el fin estatutario de la Unión de París es la protección de la propiedad industrial. También define lo que ha de entenderse por propiedad industrial, señalando que ello tiene por objeto las patentes de invención, los modelos de utilidad, los diseños industriales, las marcas, los nombres comerciales, las indicaciones de procedencia o denominaciones de origen y la represión de la competencia desleal.

\section{Principio de trato nacional [artículo 2]}

El trato nacional significa que, en lo que se refiere a la protección de la propiedad industrial, cada país parte en el Convenio de París debe otorgar a los nacionales de los demás países parte la misma protección que otorga a sus propios nacionales. Además es uno de los pilares del sistema de protección internacional establecido por el Convenio de París. Garantiza que los extranjeros no sufran discriminación.

La regla del trato nacional se aplica ante todo a los «nacionales» de los países miembros. El término «nacional» incluye tanto a las personas naturales como a las personas jurídicas, incluidas en esta última categoría las empresas de propiedad estatal u otras entidades creadas por el derecho público. Las personas jurídicas constituidas conforme al derecho privado de un país miembro se consideran generalmente nacionales de ese país. Si tienen su sede efectiva en otro país miembro, también pueden ser consideradas nacionales del país de la sede.

La regla del trato nacional se aplica a todas las ventajas que las diversas leyes internas conceden a los nacionales. Esto significa que la ley nacional debe aplicarse también a los nacionales de los demás países miembros. 
Esto significa, además, que está excluida cualquier exigencia de reciprocidad en la protección. La aplicación del derecho del país a los nacionales de otro país miembro no impide, sin embargo, que esos nacionales invoquen los derechos previstos específicamente en el Convenio de París cuando éstos fuesen más ventajosos que la legislación nacional. Empero, quedan reservadas las disposiciones nacionales relativas al procedimiento judicial y administrativo, a la competencia de las autoridades y a los requisitos de representación. Esto significa que ciertas exigencias de índole procesal que imponen condiciones especiales a los extranjeros para los fines del procedimiento judicial y administrativo, pueden invocarse también válidamente contra los extranjeros que son nacionales de países miembros. Por ejemplo, podría exigirse que los extranjeros depositen una garantía o fianza respecto de las costas judiciales. Otro ejemplo, mencionado expresamente, es que los extranjeros constituyan domicilio a los efectos de las notificaciones o bien designen un mandatario en el país en el que se solicite la protección. Esto último es probablemente el requisito especial más común que se impone a los extranjeros, y constituye una excepción permitida respecto de la regla del trato nacional.

\section{Asimilación de domiciliados a la condición de nacionales [artículo 3]}

Esta norma complementa la disposición sobre el trato nacional. Las personas que tuviesen un domicilio o un establecimiento industrial o comercial efectivo y serio en el territorio de alguno de los países de la Unión son asimiladas a la condición de nacionales de los países de la Unión. En otras palabras, debe existir una efectiva actividad industrial o comercial. No bastaría un simple apartado o casilla postal, o el arrendamiento de una pequeña oficina sin actividad real. La calificación del establecimiento como «efectivo y serio» incumbirá en cada caso a las autoridades del país en que se pretenda hacer valer esta norma.

\section{Derecho de prioridad [artículo 4]}

El derecho de prioridad significa que, sobre la base de la presentación regular de una solicitud para proteger un derecho de propiedad industrial en uno de los países miembros de la Unión de París, el mismo solicitante o su 
causahabiente puede, durante un plazo determinado, solicitar protección para el mismo objeto en todos los demás países miembros. Estas solicitudes posteriores se tratan, para efectos de determinar la prelación en el derecho, como si se hubieran presentado el mismo día que la primera solicitud (la solicitud prioritaria). Del mismo modo, gozan de un derecho de prioridad respecto de las solicitudes relativas a la misma invención presentadas con posterioridad a la fecha de la primera solicitud. Gozan también de un derecho de prioridad sobre todos los actos realizados después de esa fecha que normalmente serían aptos para anular los derechos del solicitante.

El derecho de prioridad sólo puede basarse en la primera solicitud del mismo objeto de propiedad industrial, que debe haberse presentado en un país miembro. No es posible, por lo tanto, presentar después de la primera solicitud una segunda, eventualmente mejorada, y utilizar esta última como base de la prioridad. La razón de esta regla es evidente: no puede permitirse una cadena indefinida de reivindicaciones de prioridad para el mismo objeto, pues ello podría prolongar considerablemente el plazo de protección que le correspondería al objeto de la solicitud.

El derecho de prioridad es independiente de los demás derechos que pudiera tener el solicitante en virtud de la solicitud que hubiese presentado en el país de origen. El derecho de prioridad puede cederse a terceras personas junto con el derecho de solicitar la patente o el registro en otros países en la Unión de París, y tales terceros gozarán del beneficio de la prioridad de la solicitud inicial. El derecho de prioridad es un derecho autónomo hasta el momento en que se hace valer solicitando una patente o un registro en un país, y en ese momento deviene un derecho accesorio a la solicitud presentada. Esto hace posible que se transfiera el derecho de prioridad a diferentes personas respecto de distintos países, práctica bastante usual.

La solicitud posterior debe referirse al mismo objeto que la primera, cuya prioridad se reivindica. En otras palabras: el objeto de las dos solicitudes debe ser el mismo. No obstante, puede utilizarse una primera solicitud de patente de invención como base de prioridad para el registro de un modelo de utilidad, y viceversa. El mismo cambio de modalidad de protección es posible también, en ambos sentidos, entre los modelos de utilidad y los diseños industriales.

El retiro, abandono o denegación de la solicitud prioritaria después de 
su presentación válida no perjudica su aptitud para servir como base de la prioridad. El derecho de prioridad subsiste aun cuando la solicitud prioritaria haya dejado de existir.

Como consecuencia del derecho de prioridad, una solicitud posterior que reivindica la prioridad debe ser tratada como si hubiera sido presentada en la fecha de la primera solicitud. En virtud del derecho de prioridad, ningún acto realizado durante el intervalo entre las fechas de presentación de la primera solicitud prioritaria y de la posterior que reivindica la prioridad puede afectar los derechos que emanan de esa solicitud posterior. Por ejemplo, una solicitud de patente presentada durante ese intervalo por un tercero respecto de la misma invención no da lugar a un derecho prioritario a pesar de haber sido presentada con anterioridad a la solicitud posterior. Del mismo modo, la divulgación de la invención hecha durante el período de prioridad, no destruiría la novedad o el carácter inventivo de la misma.

La duración del plazo de prioridad varía según los tipos de derechos de propiedad industrial. Para las patentes de invención y los modelos de utilidad el plazo de prioridad es de 12 meses; para los diseños industriales y las marcas es de seis meses.

El derecho de prioridad permite reivindicar «prioridades múltiples» y «prioridades parciales». En consecuencia, la solicitud posterior puede reivindicar no sólo la prioridad de una solicitud anterior, sino también combinar la prioridad de varias solicitudes anteriores, correspondientes a diferentes características del objeto de la solicitud posterior. Asimismo, en la solicitud posterior, los elementos para los cuales se reivindica la prioridad pueden combinarse con elementos respecto de los cuales no se reivindica prioridad alguna. Sin embargo, en todos estos casos la solicitud posterior debe satisfacer el requisito de unidad de invención.

Estas posibilidades responden a necesidades prácticas. Con frecuencia, después de una primera presentación, la invención es objeto de perfeccionamientos y adiciones que son materia de nuevas solicitudes en el país de origen. En esos casos, resulta sumamente práctico que se puedan combinar esas solicitudes anteriores en una única solicitud posterior, al presentarla en otro país miembro antes del vencimiento del año de prioridad. 


\section{Disposiciones relativas a las patentes}

\section{a) Independencia de las patentes [artículo 4bis]}

La regla relativa a la «independencia» de las patentes significa que éstas deben tratarse con independencia de las patentes solicitadas u obtenidas para la misma invención en otros países, incluidos los países no miembros de la Unión de París.

Este principio debe interpretarse en su sentido más amplio. Significa que el otorgamiento de una patente en un país respecto de una invención determinada no obliga a ningún otro país miembro a conceder una patente para la misma invención. El principio significa también que una patente no puede ser denegada, invalidada ni cancelada en ningún país miembro por razón de que se haya denegado o invalidado una patente para la misma invención en cualquier otro país, o que haya caducado o haya sido cancelada la patente en otro país.

La razón en que se funda el principio de independencia de las patentes, y el principal argumento en favor de él, es que las leyes nacionales y las prácticas administrativas suelen ser muy diferentes de un país a otro. La decisión de no conceder o de invalidar una patente en un país, muchas veces carece de fundamento en otro. Así, no se justificaría cancelar o revocar una patente en un país porque en otro país se hubiera cancelado la patente, por ejemplo, como consecuencia de la omisión del pago de una tasa anual en ese país o de la invalidación de la patente en ese país por una causal que no existe en las leyes de otros países. Además, un sistema en que las patentes dependieran de patentes extranjeras no estaría en conformidad con la regla del trato nacional.

Las patentes concedidas sobre solicitudes en que se reclamó la prioridad de una o más solicitudes extranjeras deben tener la misma duración que habrían tenido conforme al derecho interno si no se hubiera reivindicado ninguna prioridad. En tal sentido, no cabe deducir el plazo de prioridad del plazo de duración de la patente concedida respecto a una solicitud en la cual se reivindica una prioridad. 


\section{b) Mención del inventor en la patente [artículo 4ter]}

El Convenio de París establece para esta cuestión una regla general. Dice que el inventor tiene el derecho de ser mencionado como tal en la patente.

Las leyes nacionales pueden dar cumplimiento a esta disposición en formas diversas. Algunas sólo dan al inventor una acción civil contra el solicitante o titular a fin de obtener la inclusión de su nombre en la patente. La tendencia generalizada es a exigir de oficio, durante el procedimiento de otorgamiento de la patente, que se indique el nombre del inventor.

\section{c) Patentamiento en caso de restricción legal de la venta [artículo 4quater]}

No puede denegarse o invalidarse una patente por razón de que se encuentre prohibida la venta o comercialización del producto patentado o el procedimiento obtenido por un procedimiento patentado, o que tales actividades estén sujetas al cumplimiento de disposiciones especiales previstas en la legislación nacional. En esos casos, los países miembros quedan obligados a conceder la patente, aun cuando su titular no pudiera luego fabricar, usar o comercializar el invento patentado. Esta disposición denota una separación entre la normativa sobre patentes y la normativa relativa a la producción o distribución de productos, siendo la intención que cada una opere y se aplique independientemente de la otra.

\section{d) Importación, explotación industrial y licencias obligatorias [artículo 5A]}

\section{i) Importación}

El Convenio establece que la introducción (importación) por el titular de la patente, en el país donde la patente ha sido concedida, de objetos cubiertos por ella y fabricados en otro país de la Unión, no provocará la caducidad de la patente.

Este artículo se aplica al titular, incluido su representante o cualquiera que en su nombre lleve a cabo la importación, que, teniendo una patente en 
uno de los países de la Unión, importa productos cubiertos por la patente. En tal caso, no puede declararse la caducidad de la patente en el país de importación como sanción por tal importación.

Con respecto a los productos que se importan, basta que hayan sido fabricados en un país de la Unión. No impide la aplicación de esta disposicion el hecho de que los productos hayan circulado posteriormente en otros países y hayan sido luego importados a partir de un país que no sea miembro de la Unión.

La expresión «caducidad» que figura en el artículo 5A.1), incluye cualquier medida que tenga el efecto de cancelar definitivamente la patente. Por lo tanto, abarca los conceptos de invalidación, revocación, anulación, derogación y otros con el mismo efecto de poner fin a la vigencia de la patente.

\section{ii) Falta de explotación industrial y licencias obligatorias}

Con respecto a la explotación industrial de las patentes y las licencias obligatorias, cada país queda en libertad de dictar medidas legislativas que establezcan el otorgamiento de licencias obligatorias. Éstas tienen por objeto impedir o remediar las consecuencias de un eventual abuso de los derechos exclusivos otorgados por la patente.

La concesión de licencias obligatorias fundadas en una falta o insuficiencia de explotación industrial de una invención patentada se prevén en las leyes de varios países como medidas para remediar el defecto de explotación de la patente.

El principal argumento planteado en favor de la explotación industrial de la invención patentada consiste en que, a fin de promover la industrialización del país, las patentes de invención no deben utilizarse meramente para impedir la explotación industrial de la invención o para defender una importación exclusiva del artículo patentado. Más bien, las patentes deben servir para generar en el país el uso de nuevas tecnologías, con la consiguiente creación de empleo, riqueza y progreso tecnológico ${ }^{14}$.

${ }^{14}$ En tiempos más recientes, este enfoque tiende a ceder ante uno que privilegia 
El Convenio de París prevé que las licencias obligatorias no pueden solicitarse antes de transcurrido un plazo de cuatro años contados de la fecha de presentación de la solicitud de patente, o tres años contados de la fecha de concesión de la patente, aplicándose el plazo que vence más tarde. Del mismo modo, debe otorgarse al titular de la patente un plazo mayor si puede justificar su inacción con causas legítimas, para lo cual el titular puede presentar pruebas acreditando la existencia de obstáculos que le han impedido explotar industrialmente la invención en el país, o darle una explotación industrial más intensiva. Si se prueban tales circunstancias, debe rechazarse la solicitud de licencia obligatoria mientras ellas subsistan. El plazo de tres o de cuatro años es un plazo mínimo también en el sentido de que las leyes nacionales pueden establecer un plazo mayor si lo desearan.

Las licencias obligatorias deben ser «no exclusivas» y sólo pueden transferirse junto con la parte de la empresa que se beneficia de tal licencia. El titular de la patente debe conservar el derecho de otorgar otras licencias no exclusivas y de explotar industrialmente la invención por sí mismo. Además, como la licencia obligatoria se otorga a determinada empresa sobre la base de la capacidad que se le conoce, queda ligada a esa empresa y no puede ser transferida separadamente de ella.

Cabe mencionar que las disposiciones especiales sobre licencias obligatorias que figuran en el artículo 5A se aplican únicamente a las licencias obligatorias por falta o insuficiencia de explotación industrial. No rigen para las licencias obligatorias las disposiciones que las leyes nacionales pudieran establecer por otras razones, tales como, precios excesivos o condiciones abusivas impuestas para la concesión de licencias contractuales, $u$ otras prácticas vinculadas con una restricción de la competencia o el abuso de una posición dominante en el mercado.

El Convenio tampoco trata de las licencias obligatorias por consideraciones de interés público, por ejemplo, en la esfera de la seguridad nacional o por causa de emergencia pública, o en los casos de «dependencia» entre

más el comercio internacional de productos que su fabricación industrial en todos los países en que se concede una patente para un invento determinado. Generalmente, la explotación industrial de un invento en todos los países en que se patenta no resultaría económicamente viable. 
patentes. Estas últimas se prevén en las leyes nacionales para los casos en que no fuese posible explotar industrialmente una invención patentada sin usar una invención anterior patentada a nombre de otra persona.

\section{e) Importación de productos obtenidos por un procedimiento patentado [artículo 5quater]}

El Convenio estipula que el titular de una patente de procedimiento tendrá, respecto a productos importados en el país en que se concedió la patente, los derechos que tendría si tales productos hubiesen sido fabricados en ese país. En tal virtud, el lugar de fabricación de los productos no afectará la aplicación de los derechos resultantes de una patente de procedimiento.

Cabe observar, contrariamente a lo que pudiera parecer, que el alcance de los derechos conferidos por una patente de procedimiento queda determinado por la ley del país en que se otorgo. El artículo 5quater remite expresamente a los derechos que la legislación del país de importación concede al titular de la patente de procedimiento con respecto a los productos fabricados en ese país. Su objeto se limita a asimilar los productos fabricados en el extranjero mediante el procedimiento patentado, a los productos fabricados en el país mediante ese procedimiento.

\section{Disposiciones relativas a las marcas}

\section{a) Uso de las marcas [artículo $5 \mathrm{C}$ ]}

Algunos países exigen que las marcas, una vez registradas, se usen en el comercio dentro de cierto plazo. Si no se cumple tal exigencia, el registro de la marca puede ser cancelado. A estos efectos, suele entenderse por uso de la marca la venta, en el país de registro, de productos o servicios que llevan la marca o, en algunos casos, la exportación de los productos (o servicios) con la marca. Sin embargo, la ley nacional puede definir más ampliamente la forma como se puede llevar a cabo dicho uso. El Convenio dispone que cuando se exige el uso de la marca, el registro sólo puede ser anulado por falta de uso después de un plazo equitativo y únicamente si el interesado no justifica las causas de su inacción. En cualquier caso, la definición de lo 
que se entiende por «plazo equitativo» queda librada a la legislación interna, o a las autoridades competentes en la materia. Este plazo tiene por objeto permitir que el titular de la marca cuente con el tiempo y la oportunidad para preparar y llevar a cabo el uso, teniendo en cuenta que en muchos casos el titular debe utilizar su marca en varios países.

La cancelación del registro por falta de uso sólo puede resolverse si el titular no justifica su omisión y únicamente sería aceptable si se fundara en circunstancias jurídicas o económicas que escapan al control del titular, como sería el caso de la prohibición de la importación de los productos a los que se aplica la marca.

El empleo de una marca bajo una forma que difiera por elementos que no alteren el carácter distintivo de la marca en la forma en que ésta ha sido registrada en uno de los países de la Unión, no ocasionará la invalidación del registro ni disminuirá la protección concedida a la marca. El propósito de esta disposición es admitir diferencias menores intrascendentes entre la marca tal como ha sido registrada y la marca tal como es usada, por ejemplo, en casos de adaptación o traducción de ciertos elementos. Empero, la decisión de si las diferencias entre la marca registrada y la forma en que se utiliza efectivamente alteran o no su carácter distintivo, es asunto que corresponde a las autoridades nacionales.

El uso de una marca para productos idénticos o similares por dos o más establecimientos considerados como copropietarios de la misma, no impedirá su registro ni disminuirá su protección, siempre que su uso no tenga por efecto inducir al público a error y no sea contrario al interés público. Sin embargo, esta norma no se aplica al caso de la utilización simultánea de una marca por empresas que no son copropietarias de ella, por ejemplo, cuando la utilizan el titular y un licenciatario. El régimen aplicable a estos casos será el previsto en la legislación nacional.

\section{b) Plazo de gracia para el pago de tasas de renovación [artículo 5bis]}

El Convenio obliga a conceder un plazo de gracia para el pago de las tasas de mantenimiento de los derechos de propiedad industrial. En el caso de las marcas, esta disposición se aplicaría al pago de las tasas de renovación. Por lo general, la falta de renovación del registro puede dar lugar a su caducidad 
$y$, en algunos casos, extingue el derecho exclusivo sobre la marca. El plazo de gracia dispuesto por el Convenio de por lo menos seis meses, tiene por objeto reducir el riesgo de que se pierda el derecho sobre una marca por una omisión o retraso involuntario en el pago de las tasas de renovación. Durante el plazo de gracia, el registro permanece en vigor provisionalmente.

\section{c) Independencia de las marcas [artículo 6]}

El Convenio establece el principio de la independencia de las marcas en los diferentes países de la Unión y, en particular, sobre las presentadas o registradas en el país de origen respecto de las presentadas o registradas en otros países de la Unión.

Esta norma resulta de la aplicación del principio de trato nacional. Independientemente del origen de la marca cuyo registro se procura, los países miembros pueden aplicar sólo su legislación interna al determinar las condiciones de presentación y de registro de una marca. La aplicación del principio del trato nacional reafirma la regla de la independencia de las marcas, ya que su registro y mantenimiento sólo dependerán de la ley interna de cada país.

La solicitud de registro de una marca, presentada en cualquier país de la Unión por una persona que tenga derecho a los beneficios del Convenio, no podrá ser rehusada, ni podrá cancelarse el registro, por motivo de que no haya sido presentada, registrada o renovada en el país de origen. Esta disposición establece que la obtención y mantenimiento del registro de una marca en cualquier país de la Unión no puede depender de la solicitud, registro o renovación de la misma marca en el país de origen. Por consiguiente, para obtener el registro de una marca en un país no puede exigirse el cumplimiento de ningún requisito previo respecto de ella en el país de origen.

Se dispone que una marca regularmente registrada en un país de la Unión será considerada como independiente de las marcas registradas en los demás países de la Unión, comprendiéndose en ello el país de origen. Esto significa que una marca, una vez registrada, no se verá afectada por ninguna decisión tomada respecto de registros similares hechos en otros países para la misma marca. En este sentido, el hecho de que uno o más de tales regis- 
tros similares sean objeto, por ejemplo, de renuncia, cancelación o abandono, no afectará por sí solo a los registros de la marca en otros países. La validez de estos registros sólo dependerá de las disposiciones aplicables conforme a las leyes de cada uno de los países respectivos.

\section{d) Marcas notoriamente conocidas [artículo 6bis]}

El Convenio obliga a los países miembros a rehusar o cancelar el registro y a prohibir el uso de una marca que sea susceptible de crear confusión con otra marca ya notoriamente conocida en ese país miembro. Esta disposición reconoce la protección que se debe a las marcas que son notoriamente conocidas en un país miembro, aun cuando no estén registradas en él.

La protección de las marcas notoriamente conocidas se justifica en razón de que una marca que ha adquirido prestigio y reputación debe generar un derecho en favor de su titular a los efectos de evitar que haya un aprovechamiento indebido de ese prestigio por un tercero, y una situación de confusión en perjuicio del público. El registro o uso de una marca similar susceptible de producir confusión sería un acto de competencia desleal y lesionaría los intereses del público, que se vería inducido en confusión o error por el uso de la marca conflictiva para los mismos productos u otros idénticos a aquellos para los cuales está registrada.

La marca en cuestión debe ser «notoriamente conocida». Ello tendría que ser apreciado y determinado por las autoridades administrativas o judiciales competentes del país en que se pretenda la protección de la marca. Una marca que no ha sido usada comercialmente en un país puede, no obstante, ser notoriamente conocida en él debido a la publicidad que ahí se efectúa o a las repercusiones que tiene en el país la publicidad hecha en otros países. Sin embargo, algunos países exigen que la marca se haya usado efectivamente en el país como condición para acordarle la protección especial como marca notoriamente conocida.

La protección de una marca notoriamente conocida en virtud del artículo 6 bis es obligatoria cuando ésta ha sido presentada, registrada o usada para productos idénticos o similares. Es decir que se aplica a estos efectos la regla de la especialidad, según la cual la protección se acuerda en función de los productos que la marca distingue. Corresponderá a las autorida- 
des administrativas o judiciales del país en que se reclame la protección determinar si esta condición se cumple o no. El Convenio no impide que los países miembros acuerden a las marcas notorias una protección más amplia que la prevista en el artículo 6 bis, por ejemplo, sin limitar su aplicación con la regla de la especialidad.

Los países miembros están obligados a tomar de oficio, cuando su legislación lo permita, o a pedido de parte interesada, los siguientes tipos de medidas:

- denegar la solicitud de registro de la marca;

- cancelar el registro, para lo cual deben conceder como mínimo un plazo de cinco años a partir de la fecha de registro para pedir su cancelación, a menos que ésta hubiera sido registrada de mala fe, en cuyo caso no puede limitarse el plazo; y

- prohibir su uso, para lo cual pueden fijar un plazo, salvo cuando la marca conflictiva se usara de mala fe.

\section{e) Emblemas de Estado, signos oficiales de control y emblemas de organizaciones internacionales [artículo 6ter]}

El Convenio obliga a los países miembros, a rehusar o anular el registro, y a prohibir la utilización, bien sea como marcas o como elementos de ellas, de ciertos signos distintivos pertenecientes a los países miembros y a ciertas organizaciones internacionales intergubernamentales. Los signos distintivos de Estados mencionados en el artículo 6ter son los siguientes: los escudos de armas, banderas y otros emblemas, signos y punzones oficiales de control y de garantía, así como toda imitación de ellos desde el punto de vista heráldico.

Esta disposición no tiene como propósito crear derechos de propiedad industrial en favor de los Estados o las organizaciones intergubernamentales, sino impedir la utilización de esos signos como marcas en las actividades industriales o comerciales.

La norma del artículo 6ter no se aplica si las autoridades competentes 
del país miembro permiten la utilización de sus signos distintivos como marcas. Del mismo modo, las autoridades competentes de las organizaciones intergubernamentales pueden permitir a otros que utilicen sus signos distintivos en calidad de marcas. Además, los nacionales de cualquier país miembro que estén autorizados a utilizar los signos distintivos de sus países pueden hacerlo aun cuando esos signos sean similares a los de otro país miembro.

Para poner en práctica las disposiciones del artículo 6ter, se establece en él un procedimiento por el cual los signos distintivos de los países miembros y las organizaciones intergubernamentales interesadas se comunican a la Oficina Internacional de la OMPI, la que a su vez transmite esas comunicaciones a todos los países miembros.

\section{f) Transferencia de las marcas [artículo 6quater]}

Esta disposición concierne al caso en que una empresa es titular de una marca en varios países de la Unión y desea transferir sus derechos en alguno de esos países, reservándose la titularidad de la marca en los demás países. Se ha tenido en cuenta que en algunos de los países miembros la marca no puede transferirse independientemente de la empresa o negocio que es titular de ella o que la usa en el país. Para estos casos el Convenio establece que bastará para la validez de la transferencia de una marca en un país miembro que la parte de la empresa o del negocio situada en ese país sea transferida con el derecho exclusivo de fabricar o de vender ahí los productos que llevan la marca transferida.

De este modo, un país miembro podrá disponer que para la validez de la cesión de una marca, deberá transferirse simultáneamente la empresa a la que la marca pertenece; pero tal requisito no podrá extenderse a las partes de la empresa que están situadas en otros países. Cabe observar que cada vez son menos los países cuya legislación limita o condiciona la cesión de marcas a una cesión simultánea de la empresa o de parte de la empresa titular, siendo la tendencia actual la de una cesión libre de las marcas.

Sin embargo, los países miembros tienen la facultad de no admitir la cesión de una marca cuando su uso por el cesionario fuese de naturaleza tal que pudiera inducir al público en error, en particular en lo que se refiere a la 
procedencia, la naturaleza o las cualidades sustanciales de los productos a los que se aplica la marca. Esta facultad podría ejercerse, por ejemplo, si se transfiriera una marca sólo para una parte de los productos a los que se aplica, y esos productos fuesen similares a otros respecto de los cuales la marca no se transfiere.

\section{g) Protección de una marca «tal cual» [artículo 6quinquies]}

Paralelamente al principio de la independencia de las marcas, que figura en el artículo 6, el Convenio establece una regla especial en beneficio de los titulares de marcas registradas en su país de origen. Esta regla constituye una excepción al principio de la independencia de las marcas.

Las disposiciones del artículo 6quinquies operan cuando el registro efectuado en el país de origen se invoca en el país en el que se solicita la protección. Aunque la norma sobre el trato nacional y el principio de independencia conducen a la regla normal de la total independencia de los registros de marcas, en la situación excepcional regulada por el artículo 6quinquies rige la regla opuesta, que da efectos extraterritoriales al registro efectuado en el país de origen.

Existen dos razones principales para esta regla especial. Por un lado, conviene tanto a los titulares como al público que las mismas marcas se apliquen a los mismos productos en los diferentes países. Por otra parte, existen algunas diferencias importantes en las leyes internas de los países miembros en lo que respecta al registro de las marcas. Como consecuencia de ello, las diferencias de la legislación interna pueden impedir esta utilización uniforme de las mismas marcas. La norma del artículo 6quinquies tiene el efecto de reducir el impacto de estas diferencias sobre el registro de las marcas respecto de los productos en el comercio internacional, e impone cierta armonización entre los países miembros respecto de los fundamentos de denegación de un registro.

Para que se aplique el artículo 6quinquies, es preciso que la marca de que se trate esté debidamente registrada en el país de origen. No basta la simple presentación de la marca ni su utilización en ese país. Por otra parte, el país de origen debe ser un país de la Unión en que el solicitante tenga un establecimiento comercial efectivo y serio, o donde tenga su domicilio, o 
bien el país de la Unión del que el solicitante sea nacional. Toda marca que cumpla las condiciones exigidas debe ser admitida para su registro y protegida en los demás países miembros tal cual, sin perjuicio de ciertas excepciones.

Debe señalarse que la regla sólo atañe al aspecto formal del signo que constituye la marca, y no afecta a las cuestiones relativas a la naturaleza o función de las marcas. Así, los países miembros no están obligados a registrar ni a dar protección a un objeto que no quepa dentro del concepto de marca conforme a la ley del país respectivo. Si, por ejemplo, según la ley de un país miembro no se consideran marcas las melodías o los signos olfativos, ese país no estaría obligado a admitir tales signos para su registro ni a brindarles protección.

Se estipulan ciertas excepciones a la obligación de aceptar una marca «tal cual» para su registro en los demás países de la Unión. La lista de excepciones es exhaustiva pues no puede invocarse ningún otro fundamento para denegar o invalidar el registro de una marca solicitada al amparo del artículo 6quinquies. Esas excepciones están basadas en las siguientes causales:

i) que la marca afecte derechos adquiridos por terceros en el país en que se pide la protección: puede tratarse de derechos correspondientes a marcas protegidas en el país respectivo o de otros derechos, como los correspondientes a un nombre comercial o a un derecho de autor;

ii) que la marca esté desprovista de carácter distintivo, o sea puramente descriptiva o consista en una denominación genérica;

iii) que la marca sea contraria a la moral o al orden público, según los criterios aplicables en el país en que se solicita la protección, lo cual abarca, en particular, el caso de las marcas aptas para engañar al público;

iv) que el registro de la marca constituya un acto de competencia desleal;

v) que la marca sea utilizada por el titular en una forma esencialmente diferente de la forma en que ha sido registrada en el país de origen, pero las diferencias no esenciales no pueden servir como fundamento para rehusar el registro o invalidarlo. 


\section{h) Marcas de servicio [artículo 6sexies]}

Una marca de servicio es un signo utilizado por empresas que ofrecen servicios (no productos), como son, por ejemplo, los hoteles, restaurantes, compañías de aviación, agencias de viajes, empresas de alquiler de automóviles, agencias de empleo, lavanderías, etc. La marca de servicio permite distinguir los servicios de tales empresas de los que ofrecen otras. De este modo, las marcas de servicio cumplen las mismas funciones que las marcas de productos.

El artículo 6sexies fue introducido en el Convenio de París en 1958 con el fin de tratar específicamente de las marcas de servicio; pero la Conferencia de revisión no aprobó una propuesta de alcance mayor por la cual las marcas de servicio se habrían asimilado totalmente a las marcas de productos. Cada país miembro queda en libertad para aplicar a las marcas de servicio las mismas reglas que aplique a las marcas de productos en situaciones o condiciones similares.

Los países miembros se comprometen a proteger las marcas de servicio, pero no están obligados a registrarlas. Los países miembros tampoco estarían obligados a legislar expresamente sobre las marcas de servicio. Cada país miembro puede cumplir la disposicion, no sólo mediante leyes especiales para la protección de las marcas de servicio, sino también otorgándoles protección por otros medios, por ejemplo, aplicando las normas sobre la represión de la competencia desleal.

\section{i) Naturaleza de los productos a los que se aplica la marca [artí- culo 7]}

El Convenio dispone que la naturaleza del producto al que la marca ha de aplicarse no puede, en ningún caso, ser obstáculo para el registro de la marca. El propósito de esta norma consiste en que la protección de la propiedad industrial sea independiente de la posibilidad de comercializar o producir en determinado país los productos a los que ha de aplicarse la marca.

Puede ocurrir que una marca se refiera a productos que, por ejemplo, no cumplan los requisitos de seguridad impuestos por la ley de determinado país. Por ejemplo, las leyes de un país sobre alimentos y productos farma- 
céuticos pueden imponer requisitos relativos a los ingredientes de los productos alimenticios o a los efectos de los productos farmacéuticos y permitir su venta únicamente después de su aprobación por las autoridades competentes, otorgada sobre la base de un examen del producto alimenticio o de ensayos clínicos sobre los efectos del empleo del producto farmacéutico en seres humanos o animales.

\section{j) Marcas colectivas [artículo 7 bis]}

Una marca colectiva puede definirse como un signo que sirve para distinguir el origen geográfico, el material o modo de fabricación, la calidad u otras características comunes de los productos o servicios de diferentes empresas que utilizan simultáneamente la marca colectiva bajo el control de su titular. El titular puede ser una asociación de la que son miembros esas empresas, u otra entidad, incluso una institución pública.

El Convenio obliga a admitir la presentación de las marcas colectivas y protegerlas de conformidad con las condiciones particulares fijadas por cada país. Las entidades titulares de las marcas colectivas serán por lo general asociaciones o sindicatos de productores, fabricantes, distribuidores, vendedores $u$ otros comerciantes, que se ocupan de bienes producidos o fabricados en determinado país, región o localidad, o que tienen otras características comunes.

\section{Disposiciones relativas a los diseños industriales, nombres comerciales, denominaciones de origen e indicaciones de procedencia}

\section{a) Diseños industriales [artículos 5 B y 5quinquies]}

El Convenio establece la obligación de proteger los diseños industriales (dibujos y modelos industriales), pero guarda silencio respecto a la forma en que debe otorgarse tal protección. Los países miembros pueden cumplir esta obligación dictando leyes especiales para la protección de los diseños industriales. Sin embargo, también podrían cumplir esa obligación otorgando tal protección mediante la legislación de derecho de autor o las normas que reprimen la competencia desleal. 
El Convenio dispone que la proteccion de los diseños industriales no puede ser objeto de ninguna medida de caducidad (cancelación o revocación) como sanción por falta de explotación o por importación de objetos que incorporan el diseño industrial protegido. Sin embargo, la norma no impide que los países establezcan otras medidas adecuadas, por ejemplo licencias obligatorias, a fin de asegurar la explotación industrial en caso de falta o insuficiencia de explotación industrial o en caso de algún abuso o práctica ilícita por parte del titular.

\section{b) Nombres comerciales [artículo 8]}

El Convenio establece que el nombre comercial será protegido en todos los países de la Unión sin obligación de depósito ni de registro, forme o no parte de una marca.

La definición del nombre comercial, para los efectos de la protección, y la forma en que debe otorgarse esa protección, constituyen materias que quedan libradas a la legislación nacional de los países respectivos. Por consiguiente, la protección puede derivar de leyes especiales sobre los nombres comerciales o de leyes más generales sobre represión de la competencia desleal o los derechos relativos a la personalidad.

\section{c) Indicaciones de procedencia y denominaciones de origen [artí- culos 1.2 y 10]}

Las indicaciones de procedencia y las denominaciones de origen figuran entre los diversos objetos de la protección de la propiedad industrial definidos en el primer artículo del Convenio de París.

Estos dos conceptos pueden considerarse incluidos dentro del concepto más general de indicaciones geográficas, aunque tradicionalmente, y para los fines de ciertos tratados especiales (como el Arreglo de Madrid relativo a la Represión de las Indicaciones de Procedencia Falsas o Engañosas en los Productos, y el Arreglo de Lisboa relativo a la Protección de las Denominaciones de Origen y su Registro Internacional) se han distinguido esos dos conceptos. 
Las indicaciones de procedencia incluyen cualquier nombre, denominación o signo que haga referencia a determinado país o a un lugar situado en él, y que tenga el efecto de transmitir la noción de que los productos que llevan tal indicación se originan en ese país o lugar. Son ejemplos de indicaciones de procedencia los nombres de países (por ejemplo, Italia, Japón, etc.) o de ciudades (como New York, París, etc.).

Las denominaciones de origen tienen un alcance más limitado y pueden considerarse un tipo especial de indicaciones de procedencia. Una denominación de origen es el nombre geográfico de un país, región o localidad que sirve para designar un producto originado en él, cuya calidad y características se deben exclusiva o esencialmente al ambiente geografico, incluidos los factores naturales y humanos.

El Convenio de París contiene, en los artículos 10 y 10ter, disposiciones sobre la protección de las indicaciones de procedencia. Estas disposiciones se aplican a cualquier uso de indicaciones de procedencia falsas (incluidas, en lo aplicable, las denominaciones de origen) respecto de los productos o la identidad del productor, fabricante o comerciante, así como cualquier acto de competencia desleal consistente en el uso de indicaciones o aseveraciones susceptibles de inducir en error al público sobre la naturaleza o las características de los productos a los que se aplican.

El Convenio obliga a los países a embargar los productos que lleven falsas indicaciones o a prohibir su importación, o a aplicar otras medidas destinadas a impedir o poner término al uso de tales indicaciones. Sin embargo, la obligación de embargar los productos en el momento de la importación sólo se aplica en la medida en que tal sanción esté prevista en la legislación nacional.

El Convenio dispóne que pueden ejercer acción no sólo el Ministerio Público sino también cualquier interesado. A este respecto, el artículo 10 establece que cualquier productor, fabricante o comerciante, sea persona natural o jurídica, que se dedique a la producción, fabricación o comercio de tales productos, que esté establecido en la localidad, región o país indicado falsamente como origen o en el país en que se usan tales indicaciones falsas, debe considerarse en todo caso una parte interesada. Además, el artículo 10 ter dispone que los países deben dictar medidas que permitan a los sindicatos y asociaciones de representantes de los industriales, producto- 
res o comerciantes interesados proceder judicialmente o ante las autoridades administrativas para la represión de los actos mencionados.

\section{Medidas contra la importación de productos que lleven ilícitamente signos distintivos [artículo 9]}

El Convenio de París prevé una serie de medidas que deben aplicarse, con caracter supletorio, a fin de impedir la importación de productos que llevan ilícitamente una marca o un nombre comercial o impedir su distribución dentro del país.

Todo producto que lleve ilícitamente una marca o un nombre comercial debe ser embargado al importarse en el país en el cual la marca o el nombre comercial se encuentra protegido. Asimismo, el embargo podrá efectuarse en el país donde se hubiese hecho la aplicación ilícita del signo distintivo sobre el producto.

La norma remite a la legislación nacional para efectos de determinar quiénes pueden solicitar el embargo de los productos ilícitos. Se señala que el embargo puede realizarse a pedido del Ministerio Público, de la autoridad competente o de alguna persona interesada.

Si la legislación de un país no admitiera el embargo de la importación del producto con el signo ilícito, podría sustituirse esta medida con la prohibición de la importación o con el embargo del producto una vez internado en el país. Si la legislación del país no admitiera ninguna de las medidas anteriores, deben aplicarse las medidas que la legislación del país concediera a los nacionales para casos de importación de productos con marca ilícita.

\section{Competencia desleal [artículo 10bis]}

El Convenio dispone que los países de la Unión están obligados a asegurar una protección eficaz contra la competencia desleal. El Convenio no especifica la forma en que debe otorgarse esa protección, por lo que queda librado a las leyes de los países miembros.

El Convenio define como acto de competencia desleal todo acto de 
competencia contrario a los usos honestos en materia industrial o comercial, y a continuación enuncia, a título ilustrativo, tres actos típicos de competencia desleal.

El primer ejemplo se refiere a cualquier acto capaz de crear confusión, por cualquier medio que sea, respecto del establecimiento, los productos 0 la actividad industrial o comercial de un competidor. Estos actos incluyen no sólo el empleo de marcas o nombres idénticos o similares, que podrían impugnarse como infracciones de derechos, sino también el empleo de otros medios capaces de crear confusión. Así podría ocurrir con la forma de los envases, el arreglo o estilo de los productos y sus correspondientes salidas o puntos de distribución, títulos publicitarios, etc. El segundo ejemplo se refiere a las aseveraciones falsas en el ejercicio del comercio, capaces de desacreditar el establecimiento, los productos o la actividad industrial o comercial de un competidor. El tercer ejemplo se refiere a las indicaciones o aseveraciones cuyo empleo, en el ejercicio del comercio, pudiere engañar al público sobre la naturaleza, el modo de fabricación, las características, la aptitud en el empleo o la cantidad de los productos. Esta disposición puede diferenciarse de los casos anteriores por cuanto tiene como objeto proteger el interés del público consumidor.

\section{Recursos legales; derecho a proceder judicialmente [artículo 10ter]}

Los países de la Unión se obligan a permitir a los nacionales de los demás países de la Unión gozar de los recursos y medidas legales apropiados para reprimir eficazmente los actos de importación de productos que llevan marcas ilícitas o indicaciones falsas de procedencia y los actos de competencia desleal referidos en el Convenio de París. Ésta es una disposición de carácter amplio y general que deberán aplicar mediante su propia legislación. El Convenio no indica la manera en que esta protección deberá llevarse a cabo, exigiendo únicamente que ella sea eficaz. 


\section{El Tratado de Cooperación en Materia de Patentes (PCT)}

\section{Introducción}

El Tratado de Cooperación en Materia de Patentes, conocido por sus iniciales PCT, fue elaborado en Washington el 19 de junio de 1970, enmendado el 28 de septiembre de 1979 y modificado el 3 de febrero de $1984^{15}$. Cuenta con un Reglamento cuya última versión entró en vigor el 1 de enero de 1993. Como su nombre lo indica, el PCT es un acuerdo de cooperación internacional en materia de patentes, y se considera que denota el progreso más notable realizado en la cooperación internacional en la esfera de la propiedad industrial desde la adopción del propio Convenio de París. De hecho, se trata de un tratado destinado a racionalizar y poner bajo el mismo signo de la cooperación la presentación de solicitudes de patente, la búsqueda y el examen, así como la divulgación de las informaciones técnicas contenidas en las solicitudes. El tratado no dispone la concesión de "patentes internacionales», puesto que la tarea y la responsabilidad de otorgar las patentes compete de manera exclusiva a las oficinas que actúan en nombre de esos países (conocidas como «Oficinas designadas»). El PCT no entra en competencia con el Convenio de París, sino que lo completa. En realidad, se trata de un acuerdo especial concertado en el marco del Convenio de París y que sólo está abierto a los Estados que ya son parte en ese Convenio.

\section{Principales objetivos del PCT}

El principal objetivo del PCT es el de simplificar, hacer más eficaz y más económico —desde el punto de vista de los usuarios del sistema de patentes y de las oficinas encargadas de administrarlo- el procedimiento para solicitar la protección de una patente de invención, cuando se quiere obtener esa protección en varios países.

Cabe destacar que antes de la introducción del sistema PCT, el único medio de obtener protección para la misma invención en varios países con-

${ }^{15}$ El PCT cuenta actualmente con 56 Estados partes, entre los que se cuentan, de América Latina, Barbados y Brasil. 
sistía en presentar solicitudes separadas en cada uno de ellos; siendo así que al no guardar ninguna relación esas solicitudes entre sí, suponía una repetición de las operaciones de presentación y examen en cada país. Con el PCT estos problemas quedan resueltos, según se detallará más adelante al describir las denominadas «fase internacional» $y$ «fase nacional» respectivamente.

Del mismo modo, conviene mencionar que incluso en las oficinas de propiedad industrial que poseen una infraestructua adecuada, éstas deben enfrentarse desde hace algunos años con un excesivo recargo de trabajo (que se traduce en demoras en las concesiones de patentes) y se preguntan cuál es la mejor forma de utilizar sus medios para que el sistema de patentes brinde mejores resultados. Una de las importantes ventajas ofrecidas por el PCT es la racionalización del trabajo de las Oficinas nacionales de patentes, habida cuenta de que una parte de ese trabajo corresponde a solicitudes relativas a invenciones cuya protección también se solicita en otros países u otras regiones.

Finalmente, el PCT también tiene como objetivos asegurar que las oficinas de patentes de los Estados contratantes sólo concedan patentes sólidas; facilitar y acelerar el acceso de las industrias y de los demás sectores interesados a la información técnica relacionada con las invenciones; y ayudar a los países en desarrollo a acceder a la tecnología más moderna ${ }^{16}$.

Prueba de las innegables ventajas del sistema creado mediante el PCT es el incremento en el número de Estados partes. Así por ejemplo, en 1978 (año en que entró en vigor el tratado) alcanzaba a 18, y en la actualidad cuenta con 56. Lo mismo se puede señalar en relación con las solicitudes internacionales presentadas. Así por ejemplo, en junio de 1978, cuando se inició la aplicación del sistema de solicitudes internacionales, su número fue de 459, mientras que en 1992, de casi 26.000. Ello hace que, a finales de 1992, la Oficina Internacional de la OMPI recibiera los ejemplares originales de 145.035 solicitudes internacionales, lo que sustituye a unas 600.000 solicitudes nacionales.

${ }^{16}$ Para mayores pormenores sobre PCT, ver: «The Patent Cooperation Treaty (PCT) and its Importance to Developing Countries». Documento PCT/GEN/7 Rev.9. January 1993. Con versión en español. 
El procedimiento del PCT incluye dos fases: una fase internacional y una fase nacional. La fase internacional se refiere a la presentación y al procedimiento de búsqueda centralizados, la publicación de la solicitud, y el procedimiento de examen preliminar facultativo. La fase nacional posterior se refiere al procedimiento de concesión de las patentes por cada una de las oficinas nacionales o regionales designadas o elegidas.

\section{Fase internacional: presentación de una solicitud interna- cional; búsqueda internacional; publicación internacional}

El solicitante presenta una única solicitud denominada «solicitud internacional» en un único idioma, en una oficina (oficina receptora). Dicha solicitud tiene el efecto de una solicitud nacional regular ante todos los Estados contratantes del PCT en los que se desea la protección y en la que designa todos los Estados contratantes del PCT en los que desea obtener protección.

La oficina receptora otorga la fecha de presentación, examina la solicitud para comprobar que satisface los requisitos formales, y la transmite a la Oficina Internacional de la OMPI en Ginebra, Suiza, la que administra el sistema PCT. Al mismo tiempo, la oficina receptora transmite otra copia de la solicitud a la administración encargada de la búsqueda internacional. Dicha administración efectúa la búsqueda para encontrar publicaciones y otros antecedentes que permitan determinar el estado de la técnica respecto de la invención objeto de la solicitud. Como resultado, la administración encargada de la búsqueda internacional establece un informe en el que enumera todos los documentos que pueden tener incidencia sobre la patentabilidad de la invención reivindicada. Dicho informe es transmitido al solicitante, quien en esta etapa puede decidir presentar un pedido de examen preliminar internacional.

Tras la expiración de un plazo de 18 meses a partir de la fecha de prioridad aplicable, la Oficina Internacional publica de oficio la solicitud de patente, así como el informe de búsqueda. Al mismo tiempo, la solicitud, junto con el informe de búsqueda, son transmitidos a las oficinas nacionales de todos los Estados designados por el solicitante. Estas oficinas se denominan «oficinas designadas». Se informa al solicitante sobre esta comunicación y se le recuerda que el trámite y examen de la solicitud en las oficinas designadas, esto es, la fase nacional del proceso, comienza 20 meses 
después de la fecha de prioridad, a menos que presente un pedido de examen preliminar internacional.

\section{Fase internacional: examen preliminar internacional}

El PCT establece que el solicitante tiene la posibilidad de pedir que se realice un examen preliminar internacional de la solicitud. El objetivo de este examen es obtener una opinión técnica que permita determinar si la invención es nueva, implica una actividad inventiva y es susceptible de aplicación industrial. El solicitante debe indicar en cuáles de los Estados designados en la solicitud tiene el propósito de utilizar el resultado del examen preliminar. Estos Estados se denominan los «Estados elegidos». El pedido de examen preliminar y la elección de los Estados deben realizarse dentro del plazo de 19 meses a partir de la fecha de prioridad.

El examen preliminar es realizado por una Administración encargada del examen preliminar internacional. Normalmente, las administraciones competentes para ello son las mismas que se han especificado para la búsqueda internacional. El procedimiento puede ser comparado con el examen de fondo de la patente, incluyendo el derecho a enmendar la solicitud y a presentar argumentos.

El resultado del examen preliminar se incorpora en un informe que se transmite al solicitante y a las oficinas elegidas en las que se desee utilizar los resultados del examen. El informe proporciona una opinión respecto de los tres principales criterios de patentabilidad mencionados antes, pero no tiene efecto vinculante para los países elegidos pues las oficinas de los países no están obligadas a aceptar las conclusiones de la administración encargada del examen preliminar internacional. Otro efecto importante del procedimiento del examen preliminar, es que el inicio de la fase nacional ante las oficinas elegidas se pospone durante 10 meses adicionales. Por ello, la fase nacional comienza recién después de vencidos 30 meses contados desde la fecha de prioridad, lo cual dará al solicitante mayor tiempo para decidir si desea continuar con su solicitud y, en su caso, efectuar los preparativos correspondientes. 


\section{Fase internacional; posibilidad de enmendar la solicitud}

Durante la fase internacional, el solicitante podrá enmendar las reivindicaciones con efecto para todos los Estados designados, a fin de adaptarlas a los resultados de la búsqueda. Del mismo modo, cuando se haya presentado un pedido de examen preliminar internacional, el solicitante podrá enmendar todas las partes de la solicitud (es decir, la descripción, las reivindicaciones y los dibujos) cuando presente el pedido de examen preliminar, o durante el examen como respuesta a una observación o reparo comunicado por el examinador.

\section{Fase nacional}

La fase internacional va seguida de la fase nacional. Antes de iniciar los procedimientos de trámite y examen en la fase nacional en las oficinas que han sido designadas en la solicitud internacional, el solicitante debe realizar ciertos actos. Esto se denomina la entrada en la fase nacional. Si el solicitante no desea entrar en ella o no realiza dichos actos, la solicitud internacional pierde su efecto en los Estados designados.

Para entrar en la fase nacional será necesario pagar la tasa nacional en cada una de las oficinas designadas y, cuando la solicitud internacional no ha sido presentada o publicada en el idioma o en uno de los idiomas oficiales de la oficina, se presentará una traducción en un idioma oficial. Eso debe realizarse únicamente antes de que expire el plazo de 30 meses a partir de la fecha de prioridad, siempre que dentro del plazo de 19 meses contados a partir de esa fecha se hubiera pedido el examen preliminar internacional. De lo contrario, debe hacerse dentro del plazo de 20 meses contados a partir de la fecha de prioridad.

\section{Requisitos nacionales especiales adicionales}

Además del pago de la tasa nacional y, cuando sea aplicable, de la presentación de una traducción, ninguna oficina nacional puede exigir el cumplimiento de requisitos adicionales antes de cumplirse el plazo de 20 o 30 meses, según corresponda. Se permiten algunos requisitos adicionales, tales como la designación de un mandatario, la indicación de un domicilio para la 
entrega de notificaciones, la declaración de inventor, documentos de asignación y similares, pero el solicitante debe tener la posibilidad de satisfacer estos requisitos adicionales después de que hayan expirado los plazos antes mencionados.

\section{Enmiendas en la fase nacional}

E1 PCT brinda al solicitante la posibilidad de enmendar la descripción, las reivindicaciones y los dibujos ante cualquier oficina designada. Por lo tanto, si bien el solicitante ya ha tenido oportunidades de realizar las enmiendas durante la fase internacional, se pueden presentar enmiendas adicionales al entrar en la fase nacional o dentro del plazo que se señale.

\section{Arreglo de Madrid relativo a la Represión de las Indicaciones de Procedencia Falsas o Engañosas en los Productos}

El Arreglo de Madrid relativo a la Represión de las Indicaciones de Procedencia Falsas o Engañosas en los Productos fue concluido en Madrid en 1891, y se refiere específicamente a las medidas que deben adoptar los países miembros para evitar o reprimir la importación y distribución de productos que lleven una indicación de procedencia falsa o engañosa ${ }^{17}$. Merecen ser destacados los siguientes artículos de este tratado.

\section{Embargo de productos con indicaciones falsas [artículo 1]}

Los productos que lleven una indicación falsa o engañosa en virtud de la cual resulten designados directa o indirectamente como país o como lugar de origen alguno de los países que son miembros del Arreglo de Madrid, o algún lugar situado en alguno de ellos, deben ser embargados al momento de su importación en cualquiera de estos países.

${ }^{17}$ El Arreglo fue revisado en Washington en 1911, en La Haya en 1925, en Londres en 1934 y en Lisboa en 1958, y posteriormente complementado en Estocolmo en 1967. Actualmente 31 Estados son partes de este tratado, entre los cuales se encuentran los siguientes de América Latina: Brasil, Cuba y la República Dominicana. 
El embargo también podrá efectuarse en los países donde se hubiese colocado la indicación de procedencia falsa o engañosa, o en el lugar de donde se hubiese importado el producto provisto de tal indicación. Si la legislación no admitiera el embargo al momento de la importación, esta medida será reemplazada por la prohibición de la importación. En defecto de estas dos medidas, deberán aplicarse las que en casos parecidos conceda el país en cuestión.

\section{Derecho de colocar el nombre y dirección del vendedor [artículo 3]}

El vendedor de un producto tiene el derecho de indicar su nombre y su dirección en los productos que comercializa, aun cuando ellos procedieran de un país diferente a aquél en que se realiza la comercialización. Sin embargo, es necesario que la dirección y el nombre del vendedor sean acompañados de una indicación precisa y en caracteres visibles del país o del lugar de fabricación o de producción del producto, o de cualquier otra indicación que fuese suficiente para evitar cualquier error sobre el verdadero origen de las mercancías.

\section{Indicaciones engañosas en la publicidad [artículo 3bis]}

Los países miembros se obligan a prohibir el uso de cualquier indicación que tuviese carácter de publicidad y fuese susceptible de inducir en error al público sobre la procedencia de los productos. Ese uso podrá ocurrir con ocasión de la venta, la exhibición o el ofrecimiento de los productos referidos, pudiendo figurar sobre insignias, anuncios, facturas, tarjetas, papeles de comercio o cualquier otra clase de comunicación comercial.

\section{Denominaciones geográficas de carácter genérico [artículo 4]}

Corresponde a las autoridades judiciales de cada país decidir qué denominaciones geográficas no quedan sujetas a las disposiciones del Arreglo de Madrid por tratarse de denominaciones de caracter genérico para designar a los productos de que se trata. 
Esta disposición reconoce que ciertas denominaciones geográficas puedan constituir denominaciones genéricas de los productos a los cuales se aplican. Tales son, por ejemplo, los casos de «agua de colonia» (para aguas perfumadas), «cachemira» (para lanas), «tinta china» (referido a un tipo de tinta para escribir), "persiana veneciana» (referido a ciertos tipos de persianas), etc.

\section{Arreglo de Madrid relativo al Registro Internacio- nal de Marcas y su Protocolo}

\section{a) El Arreglo de Madrid}

El Arreglo de Madrid relativo al Registro Internacional de Marcas fue celebrado en 1891, y establece un registro internacional para las marcas y el procedimiento para su inscripción ${ }^{18}$ y está abierto a los Estados parte en el Convenio de París.

El Arreglo establece el registro de marcas (marcas de fábrica o de comercio y marcas de servicio) por la Oficina Internacional de la OMPI. Los registros en virtud de este Arreglo se llaman internacionales porque todos los registros surten efecto en varios países y pueden extenderse a todos los Estados contratantes.

El registro internacional tiene varias ventajas para el titular de la marca. En efecto, después de registrar la marca en el Estado contratante de origen, le basta con presentar una sola solicitud y pagar una sola tasa en una oficina (la Oficina Internacional), en un idioma (francés), en vez de presentar solicitudes por separado en las oficinas nacionales de marcas de los diversos Estados contratantes, en distintos idiomas y pagando sendas tasas en todas la oficinas. Las mismas ventajas existen cuando hay que renovar el registro.

\footnotetext{
18 El acta original fue posteriormente revisada en Bruselas en 1900, en Washington en 1911, en La Haya en 1925, en Londres en 1934, en Niza en 1957 y en Estocolmo en 1967. Actualmente son miembros de este tratado 33 Estados, entre ellos Cuba.
} 
El registro internacional también tiene ventajas para las oficinas nacionales de marcas, pues reduce el volumen de trabajo que, de otra forma, tendrían que efectuar. Por ejemplo, no tienen que publicar las marcas. Del mismo modo, una parte de las tasas cobradas por la Oficina Internacional es transferida a los Estados contratantes donde se solicita la protección. Además, si el Servicio de Registro Internacional cierra su balance anual con superávit, los beneficios se dividen entre los Estados contratantes. Así por ejemplo, para 1991, dicho superávit fue de más de diecisiete millones de francos suizos, que fueron repartidos entre los países miembros de la Unión de Madrid en proporción al número de designaciones que recibió cada uno de ellos.

Las ventajas descritas anteriormente quedan ratificadas por el número de registros y renovaciones que se producen anualmente. Así por ejemplo, cuando se inició el registro internacional en 1893 hubieron 76 registros, siendo 20.791 el número que corresponde para 1991. Ello además se verifica mediante un incremento persistente a través de sus más de cien años de existencia.

Merecen destacarse las siguientes disposiciones de este Arreglo:

\section{Constitución de una Unión; registro de marcas; definición de país de origen [artículo 1]}

Los países miembros del Arreglo de Madrid constituyen una Unión para el registro internacional de las marcas. Esta Unión, al igual que la Unión de París, constituye una persona jurídica de derecho público internacional, que tiene sus propios órganos rectores internos y un presupuesto que se financia mediante el cobro de tasas por los servicios que presta la Oficina Internacional por el registro internacional de marcas y otros trámites relacionados con éstas.

Los nacionales o residentes de cada uno de los países contratantes podrán obtener en todos los demás países miembros la protección de sus marcas registradas en el país de origen, mediante su registro en el registro internacional de marcas que se lleva en la Oficina Internacional de la OMPI. El registro de una marca se solicita por intermedio de la administración nacional de propiedad industrial del país de origen. 
Se define como país de origen aquel país de la Unión donde el solicitante tenga un establecimiento industrial o comercial efectivo y real. Si no lo tuviera, se considerará como país de origen el de su domicilio, y si no tuviera domicilio en ningún país de la Unión, aquel país de su nacionalidad en caso de ser nacional de un país de la Unión de Madrid.

\section{Contenido de la solicitud de registro internacional [artículo 3]}

La solicitud de registro internacional debe presentarse ante la administración nacional de propiedad industrial del país de origen de la marca. Esta administración debe certificar que la información contenida en la solicitud corresponde a la del registro nacional de la marca, y agregar la fecha y los números del registro de origen y la fecha de presentación de la solicitud de registro internacional.

La administración nacional remite la solicitud de registro a la Oficina Internacional de la OMPI, la cual registra inmediatamente la marca en su registro internacional. El registro lleva la fecha de la presentación de la solicitud de registro en el país de origen, siempre que la solicitud haya llegado a la OMPI dentro de un plazo de dos meses contados desde esa fecha. Si la solicitud se recibiera con posterioridad a esa fecha, la inscripción llevará la fecha de la recepción de la solicitud por la OMPI.

Una vez inscrita la marca en el registro, la Oficina Internacional anuncia el registro en su revista Les marques internationales y notifica la inscripción a cada uno de los países que se hubiesen designado en la solicitud. El solicitante debe indicar en su solicitud los países en los cuales quiere que el registro internacional surta efecto. Puede indicar todos los países miembros del Arreglo o solamente uno o algunos de ellos.

\section{Efectos del registro internacional [artículo 4]}

El registro de una marca en la Oficina Internacional tiene, en relación con los países que hubiesen sido designados en la solicitud, el mismo efecto que si se hubiera presentado una solicitud de registro de marca en cada uno de esos países en la fecha del registro. 


\section{Denegación por parte de las administraciones nacionales [artículo 5]}

Los países tienen la facultad de declarar, a través de sus administraciones nacionales competentes, que no pueden acordar protección a una marca inscrita en el registro internacional. La denegación de protección sólo puede sustentarse en las condiciones establecidas en el Convenio de París para la protección de la propiedad industrial. Dichas causales se encuentran estipuladas en el artículo 6quinquies párrafo B del Convenio de París.

La negativa de protección tiene que ser notificada a la OMPI dentro del plazo previsto por la legislación nacional para denegar el registro de una marca, y en ausencia de disposición, a más tardar dentro de un año contado a partir del registro internacional de la marca. En caso de no comunicarse el rechazo de protección, el país pierde el derecho de rehusarla, y se entenderá que la marca inscrita en el registro internacional se encuentra legalmente protegida en el país en cuestión.

Cuando la administración nacional notificara a la OMPI una negativa de protección, la OMPI transmitirá esta información a la administración nacional del país de origen de la marca, y al titular de la misma o a su mandatario. En este caso el interesado gozará de las mismas acciones y recursos, en el país que comunicó el rechazo, que tendría si hubiera presentado directamente a la administración nacional de ese país la solicitud de registro.

\section{Duración del registro internacional; independencia del registro internacional; cese de la protección en el país de origen [artículo 6]}

El registro internacional de marcas tiene una duración de 20 años, con posibilidad de ser renovado indefinidamente por períodos iguales. Este registro queda vinculado al registro nacional del país de origen durante cinco años, de manera que si durante este plazo el registro del país de origen llegara a caducar o fuese cancelado o anulado por cualquier razón, el registro internacional deja de tener validez en todos los países para los cuales se hubiese inscrito. Lo mismo ocurre cuando la protección legal en el país de origen hubiese cesado con posterioridad al plazo de cinco años, si ello fuese consecuencia de una acción iniciada durante ese plazo. 
Al vencer el plazo de cinco años contados desde la fecha del registro internacional, este registro se hace independiente del registro de la marca en el país de origen, de manera que la marca internacional queda protegida en todos los países para los cuales se hubiese efectuado el registro internacional.

Sin perjuicio de lo anterior, el registro internacional de una marca puede ser anulado individualmente en cada uno de los países en que éste surte efecto, pero ello deberá gestionarse ante las instancias competentes de cada uno de los países en que deseara obtenerse la anulacion. En este sentido, la anulación se tramitará como si se tratara de la anulación de un registro nacional. Tal anulación sólo surtirá efectos en el país en que se obtuviera.

\section{Renovación del registro internacional [artículo 7]}

El registro internacional de la marca puede ser renovado por períodos sucesivos de 20 años contados a partir de la fecha de vencimiento del período precedente, bastando para ello pagar las tasas establecidas.

La renovación de la marca se entiende como una simple prolongación del registro inicial. En tal sentido no puede dar lugar a ninguna modificación del signo registrado, ni a ninguna ampliación de la lista de productos o de servicios cubiertos por la misma. La marca queda renovada tal como fue inscrita en el registro inicial.

Se prevé un plazo de gracia de seis meses después del vencimiento del plazo del registro internacional para solicitar su renovación, debiendo en tal caso pagarse el recargo respectivo.

\section{Tasa nacional y tasa internacional; reparto de los excedentes de ingresos [artículo 8]}

El registro de una marca en la Oficina Internacional en la OMPI está sujeto al pago de una tasa internacional que comprende una tasa básica, una tasa suplementaria por cada clase de la clasificación internacional, después de la tercera, en la que queden clasificados los productos o servicios a los que se 
aplica la marca, y un complemento de tasa que se paga en función del numero de países que se hubiese designado en la solicitud para el alcance territorial del registro internacional. El producto anual de los diferentes ingresos del registro internacional se reparte entre los países miembros de acuerdo con los criterios estipulados para tales efectos.

\section{Transmisión de una marca internacional que entrañe un cambio de país del titular [artículo 9bis]}

Cuando una marca inscrita en el registro internacional fuese cedida o transferida a una persona domiciliada en un país distinto al del país del titular del registro internacional, esta transferencia deberá notificarse a la Oficina Internacional de la OMPI a través de la administración del país de origen. La transferencia es registrada y notificada a las oficinas nacionales de propiedad industrial de los países en los cuales el registro internacional surte efectos.

\section{Cesión de una marca internacional para una parte de los produc- tos o servicios o para ciertos países solamente [artículo 9ter]}

Es posible transferir una marca internacional solamente con respecto a una parte de los productos o servicios para los cuales se hubiese registrado. En este caso los países en los cuales tiene efectos el registro tendrán la facultad de rehusar el reconocimiento de la transferencia de la marca si los productos o servicios comprendidos en la transferencia fuesen similares a aquellos para los cuales la marca queda registrada en favor del titular original, y pudiese surgir un riesgo de confusión o error.

\section{b) EI Protocolo}

El Protocolo concerniente al Arreglo de Madrid relativo al Registro Internacional de Marcas (en adelante llamado «el Protocolo») fue adoptado en Madrid el 27 de junio de 1989 y constituye un complemento del Arreglo de Madrid, instituyendo un sistema análogo y paralelo al de este Arreglo. Desde su entrada en vigor en 1892, el Arreglo de Madrid brinda la posibilidad de proteger una marca en varios países mediante un único registro interna- 
cional. Aunque el sistema establecido por el Arreglo de Madrid ha sido usado extensamente durante más de un siglo, el número de países miembros en el tratado se mantuvo relativamente pequeño, y parecía poco probable que se ampliara en vista de algunas características del sistema que impedían su aceptación por ciertos países, entre ellos algunos de gran actividad en el ámbito marcario, por ejemplo los Estados Unidos de América, Japón y el Reino Unido.

Las características consideradas inaceptables por esos países eran, en particular, la necesidad de obtener primero el registro de la marca a nivel nacional antes de solicitar el registro internacional; la dependencia del registro internacional respecto del registro nacional de origen durante cinco años; el plazo relativamente corto que se acuerda a las oficinas nacionales para comunicar una denegación de protección a la marca inscrita en el registro internacional; y el sistema de tasas que no convenía los países que aplicaban tasas de registro más altas que las del Arreglo.

Con miras a resolver esos problemas se conformó un Grupo de Trabajo que se reunió tres veces entre 1986 y 1987. Durante estas reuniones se discutieron los proyectos de dos protocolos: uno para modificar el sistema del Arreglo de Madrid a fin de hacerlo aceptable para los cuatro países de la Comunidad Europea que no eran miembros del Arreglo de Madrid; y otro para establecer propiamente los vínculos entre el sistema del Arreglo de Madrid y el futuro sistema de la marca comunitaria. Posteriormente, estos dos protocolos se refundieron en uno solo, y la Asamblea de la Unión de Madrid convocó la conferencia diplomática que se realizó en Madrid en junio de 1989. Esa conferencia diplomática adoptó el «Protocolo concerniente al Arreglo de Madrid relativo al Registro Internacional de Marcas» ${ }^{19}$.

\section{Principales características del Protocolo}

El Protocolo establece un sistema de registro internacional de marcas que, en comparación con el sistema previsto en el Arreglo de Madrid, se caracteriza por lo siguiente:

${ }^{19}$ El Protocolo aún no ha entrado en vigor. Ha sido suscrito por 27 Estados y ratificado por uno, España. 
(i) Posibilidad de solicitar un registro internacional en base a una solicitud nacional

El Protocolo (art. 2.1)) prevé que el registro internacional de una marca puede ser solicitado no sólo cuando se ha obtenido el registro de base de la marca en el país de origen, sino también cuando se hubiese presentado una solicitud de registro de la marca en el país de origen («solicitud de base»). Esta modificación remueve uno de los principales obstáculos para una adhesión más numerosa al Arreglo de Madrid. Tal obstáculo consiste en que obtener un registro nacional (o regional) generalmente toma tiempo considerable, a menudo más de seis meses contados desde la fecha de presentación de la solicitud de base, con la consecuencia de que la persona interesada perdería la posibilidad de hacer valer su derecho de prioridad (que dura seis meses) de conformidad con el Convenio de París.

\section{(ii) Plazo para rehusar la protección a una marca inscrita en el registro internacional}

El Arreglo de Madrid establece que los países miembros tienen la facultad de declarar que no pueden conceder protección en sus territorios a una marca inscrita en el registro internacional. Para estos efectos la administración nacional competente del país que rehúsa la protección debe notificar su decisión, indicando los motivos, a la Oficina Internacional dentro del plazo previsto por su legislación nacional, pero a más tardar antes de finalizar un año a contar desde el registro internacional de la marca. El Protocolo establece (artículo 5.2.b)) que, sin perjuicio de lo anterior, toda parte contratante podrá declarar que, para los registros internacionales efectuados en virtud del Protocolo, el plazo de un año referido será reemplazado por un plazo de 18 meses. Además, una parte contratante podrá reservarse el derecho de denegar la protección notificando la denegación después del plazo de $18 \mathrm{me}-$ ses cuando la denegación se basara en una oposición presentada en el país. Para estos efectos, la notificación de la oposición o de la posibilidad de que se presente una oposición deberá realizarse antes del vencimiento del plazo de 18 meses, y la denegación «provisional» de la protección deberá efectuarse en un plazo máximo de 7 meses a partir de la fecha en que comience el plazo de oposición o de un mes a partir de la expiración del plazo de oposición, aplicándose el plazo que fuera más corto. 
(iii) Duración del registro internacional.

El Arreglo de Madrid prevé que el registro de una marca de la Oficina Internacional se efectúa por 20 años, con posibilidad de renovación por nuevos períodos sucesivos de 20 años contados a partir de la expiración del período precedente. El Protocolo estipula (artículo 6) que el registro de una marca en la oficina internacional se efectúa por 10 años, con la posibilidad de renovación por nuevos períodos de 10 años contados a partir de la expiración del período precedente (artículo 7). La renovación se realiza mediante el simple pago de la tasa de base y de las tasas suplementarias y los complementos de tasa previstos en el Protocolo.

\section{(iv) Posibilidad de cobrar tasas individuales en cada país.}

El Protocolo adopta un sistema de tasas y de reparto de las mismas análogo al establecido en el Arreglo de Madrid. Sin embargo, introduce una nueva posibilidad (artículo 8.7)) en virtud de la cual toda parte contratante puede declarar que desea recibir, en lugar de una parte de los ingresos procedentes de las tasas suplementarias y de los complementos de tasas, una tasa llamada «tasa individual», cuyo importe será indicado en la declaración respectiva y que podrá ser modificado en declaraciones subsiguientes. Esta tasa individual no podría exceder del equivalente del importe, deducidas las economías resultantes del procedimiento internacional, que la oficina nacional podría percibir de un solicitante por concepto de un registro de marca por diez años. En caso que correspondiera pagar la tasa individual y en la solicitud de registro internacional solamente se designan partes contratantes que han hecho la declaración respecto a la percepción de la tasa individual, el solicitante del registro quedaría eximido de pagar la tasa suplementaria. Tampoco tendría que pagarse ningún complemento de tasa con respecto a toda parte contratante designada en la solicitud que hubiera hecho la declaración de percepción de la tasa individual.

\section{(v) Transformación de un registro internacional en solicitudes naciona- les o regionales.}

El Protocolo incorpora una disposición (artículo 9quinquies), relativa a la posibilidad de transformar un registro internacional en solicitudes de registro nacionales o regionales cuando el registro internacional fuese cancelado por haberse cancelado el registro de base en el país de origen. El Arreglo 
de Madrid estipula (artículo 6.(2)) que la cancelación del registro nacional de base durante los primeros cinco años de vigencia del registro internacional causa automáticamente la cancelación del registro internacional y la cesación de sus efectos en todos los países designados en ese registro. Este efecto, llamado «ataque central», fue criticado por algunos países como uno de los inconvenientes en el Arreglo de Madrid. Con el fin de mitigar los efectos negativos del ataque central, el Protocolo estipula que la persona que era el titular del registro internacional cancelado tendrá la posibilidad de presentar una solicitud de registro para la misma marca ante la oficina nacional o regional de cualquier parte contratante designada en el registro internacional, y tal solicitud será tramitada como si hubiera sido presentada en la fecha del registro internacional cancelado. En tal virtud, el titular del registro internacional cancelado no pierde la fecha de este registro, y si el registro internacional se efectuó bajo el beneficio de un derecho de prioridad, las solicitudes nacionales presentadas por el titular gozarán de la misma prioridad. Para que esta transformación pueda operar, las solicitudes respectivas deben presentarse ante las oficinas nacionales o regionales designadas dentro de los tres meses contados a partir de la fecha de cancelación del registro internacional, y los productos y servicios listados en esas solicitudes deberán estar incluidos en la lista de productos o servicios del registro internacional cancelado. Las solicitudes nacionales o regionales resultantes de la transformación deberán satisfacer todos los requisitos de la legislación nacional o regional aplicable, incluyendo el pago de las tasas respectivas.

\section{Arreglo de la Haya relativo al Depósito Internacio- nal de Dibujos y Modelos Industriales}

\section{Introducción}

El Arreglo de La Haya relativo al Depósito Internacional de Dibujos y Modelos Industriales, fue adoptado el 6 de noviembre de 1925, y es un acuerdo particular dentro del marco del Convenio de París para la Protección de la Propiedad Industrial ${ }^{20}$.

${ }^{20}$ Sus disposiciones sustantivas han sido revisadas en dos oportunidades, a saber, en Londres en 1934 y en La Haya en 1960. Además, en revisiones posteriores realizadas en Mónaco en 1961, Estocolmo en 1967 y Ginebra en 1975, se modifica- 


\section{Principio del depósito internacional}

El depósito internacional de los diseños industriales (dibujos industriales y modelos industriales) surgió de una búsqueda de simplicidad y economía. Su objetivo principal es permitir la protección de uno o más diseños industriales en varios países mediante un único depósito efectuado ante la Oficina Internacional de la Organización Mundial de la Propiedad Intelectual (OMPI).

El Arreglo de La Haya permite a las personas que pueden acogerse a sus disposiciones efectuar un depósito internacional para proteger sus diseños industriales en varios países con un mínimo de formalidades y a un costo reducido. También se evita tener que presentar documentos en diferentes idiomas y observar plazos procedimentales y de renovación respecto de un gran número de expedientes y registros, y el pago de diferentes tasas nacionales y honorarios en diferentes monedas.

\section{Depósito internacional de un diseño industrial}

El depósito internacional de un diseño industrial puede ser efectuado por cualquier persona que sea nacional de uno de los Estados miembros del Arreglo de La Haya. Asimismo puede realizarlo cualquier persona natural o jurídica que tenga su domicilio o sede, o un establecimiento industrial o comercial real y efectivo, en alguno de los Estados miembros.

El depósito internacional no requiere que se efectúe previamente un depósito o registro nacional para el mismo diseño industrial. El depósito internacional puede hacerse directamente ante la Oficina Internacional de la OMPI. Sin embargo, se prevé la posibilidad de que el depósito pueda efectuarse a través de la oficina nacional de un Estado contratante cuando la legislación de ese Estado así lo permita (artículo 4.1).2)). La misma norma establece que un Estado contratante puede disponer que cuando ese Estado

ron las disposiciones administrativas relativas, entre otros, a las finanzas, tasas, órganos de la Unión de La Haya y la interrelación entre las actas vigentes del Arreglo y su participación en ellas por los Estados miembros. Actualmente 21 Estados son parte del Arreglo de La Haya, entre ellos Cuba. 
fuese el país de origen, el deposito internacional tendrá que hacerse a través de la oficina nacional competente de ese país. A la fecha ninguno de los Estados miembros del Arreglo de Madrid ha previsto esta condición en su legislación nacional.

\section{Efectos del depósito internacional}

\section{a) Efecto territorial}

Sin perjuicio de las disposiciones relativas a la protección de un diseño industrial en el Estado de origen, el deposito internacional puede tener efecto en todos los Estados contratantes. Sin embargo, la cobertura territorial de un depósito internacional varía por razón de encontrarse en vigencia dos actas diferentes del Arreglo de La Haya, a saber, el Acta de 1934 y el Acta de 1960. El Acta de 1934 prevé que el depósito internacional de un diseño industrial tiene efecto automático en todos los Estados vinculados a ella. En cambio, el Acta de 1960 dispone que el deposito internacional tendrá efectos solamente en aquellos Estados vinculados a esa Acta que fuesen expresamente designados por el depositante.

Dependiendo de la nacionalidad o domicilio del depositante, el efecto territorial del depósito internacional será diferente por razón de los diferentes textos del tratado que serían aplicables. Los nacionales o domiciliados en Estados vinculados tanto al Acta de 1934 como al Acta de 1960 pueden efectuar depositos internacionales con efectos en todos los Estados miembros del Arreglo de La Haya. Los nacionales o domiciliados en Estados vinculados solamente al Acta de 1934, no pueden efectuar depósitos internacionales con efectos en los Estados vinculados solamente al Acta de 1960. Del mismo modo, los nacionales o domiciliados en Estados vinculados solamente al Acta de 1960 no pueden realizar depósitos internacionales con efectos en los Estados vinculados solamente al Acta de 1934.

En lo que respecta a la protección del diseño industrial en el país de origen, las disposiciones de las Actas de 1934 y 1960 son diferentes. Según el Acta de 1934 (artículo 1) el déposito internacional no tendrá efecto en el país de origen, salvo cuando ello fuese expresamente permitido por la ley del país concernido. El Acta de 1960 dispone (artículo 7.2)) que el depósito 
internacional tiene efecto en el Estado de origen, salvo cuando la legislación nacional dispusiera otra cosa.

\section{b) Efecto jurídico}

Tanto el Acta de 1934 como el Acta de 1960 disponen que el depósito internacional de un diseño industrial tiene en cada Estado al cual fuese aplicable el mismo efecto que si el diseño hubiese sido directamente depositado en ese Estado. El Acta de 1934 estipula que el depósito producirá en los Estados contratantes los mismos efectos que si el diseño industrial hubiese sido depositado directamente en ellos en la fecha del depósito internacional; tal depósito tendrá carácter puramente declarativo (artículo 4.2)).

El Acta de 1960 estipula que la protección de los diseños industriales que hubiesen sido objeto de un registro en la Oficina Internacional se regirá en cada uno de los Estados contratantes por las disposiciones de la legislación nacional aplicables a los diseños industriales protegidos mediante un registro nacional (artículo 7.1)).

\section{Publicación}

El Acta de 1934 no prevé la publicación de la reproducción de los diseños industriales objeto de depósito internacional. Los depositos pueden efectuarse en pliego abierto o cerrado. Si un diseño industrial se deposita en pliego cerrado se conserva en reserva durante los primeros cinco años de duración de la protección internacional. Si se pide una prórroga de la protección internacional por un segundo período de vigencia (de diseños), la Oficina Internacional procede a la apertura del pliego y anuncia la prórroga concedida, notificándola además a todas las administraciones nacionales de los países miembros.

El Acta de 1960 estipula que el diseño industrial depositado en la Oficina Internacional debe ser publicado en un boletín periodico. Este boletín, llamado International Designs Bulletin, incluye las reproducciones de los diseños industriales que son objeto de depósito (artículo 6.3)). Sin embargo, el Acta de 1960 permite que el depositante solicite el aplazamiento de la publicación por un período que no podrá exceder de doce meses contados 
desde la fecha del depósito internacional o, cuando correspondiera, desde la fecha de la prioridad reivindicada.

\section{Denegación de la protección}

El Acta de 1960 estipula que cada Estado contratante cuya legislación nacional prevea la posibilidad de denegar la protección de diseños industriales en base a un examen administrativo de oficio o con base en la oposición de una tercera persona, podrá denegar la protección a un diseño industrial depositado internacionalmente cuando éste no cumpliera con los requisitos establecidos en esa legislación. La denegación deberá fundamentarse en razones sustantivas y no en razones de forma o de procedimientos.

La denegación de la protección debe comunicarse a la Oficina Internacional dentro del plazo de seis meses contados desde la fecha en que la oficina nacional del país concernido hubiese recibido el boletín en el cual se anuncia el depósito internacional. La denegación se notifica también al depositante, quien tendrá, respecto a la denegación de protección, las mismas acciones que tendría si hubiese depositado su diseño industrial directamente en el país que comunicó la denegación. Respecto a los países que no comunican una denegación dentro del plazo de seis meses, el depósito internacional surte en ellos los mismos efectos que un depósito nacional registrado directamente en el país.

\section{Duración de la protección}

El Acta de 1934 fija la duración de la protección internacional en 15 años contados desde la fecha del deposito. Este término se divide en dos períodos: un primer período de cinco años y un segundo período de diez años (artículo 7).

El Acta de 1960 estipula que el depósito internacional se efectúa por un período inicial de cinco años, pudiendo renovarse por lo menos una vez por un período adicional de cinco años para todos o para algunos de los Estados en los cuales el depósito tiene efectos. Con respecto a los Estados contratantes cuya legislación nacional permite para los dépositos o registros nacionales de diseños industriales un término de duración mayor de diez 
años, el déposito internacional podrá ser renovado por nuevos términos de cinco años con efecto en esos Estados, hasta alcanzar el plazo máximo de duración permitido para los depósitos nacionales de acuerdo con la legislación de los Estados respectivos (artículos 10 y 11 del Acta de 1960). Sin embargo, se permite a todo Estado contratante limitar la duración de la protección de los diseños industriales depositados internacionalmente a las duraciones mínimas previstas en el Acta de 1960, a saber, diez años contados desde la fecha del depósito internacional si hubiese renovación, o cinco años contados desde la fecha del depósito internacional en caso de que no hubiese renovacion.

\section{Tasas}

El Acta de 1934 establece que se cobra una tasa de depósito internacional por el primer período de cinco años y una tasa de renovación por el segundo período de diez años, de modo que el plazo total de duración de la protección internacional no puede exceder de quince años. El monto de las tasas cobradas de conformidad con el Acta de 1934 varía según el número de diseños incluidos en la solicitud de depósito, pero no en función del número de países para los cuales el depósito tendrá efecto. Los países vinculados al Acta de 1934 se consideran para estos efectos como un grupo unitario y la protección se extiende a todos ellos de manera automática.

El Acta de 1960 prevé una tasa de publicación calculada en función de la dimensión del aviso publicado en el boletín de diseños internacionales, una tasa de depósito internacional que corresponde a la Oficina Internacional, y tasas para los Estados contratantes designados por el depositante en su solicitud. El monto de la tasa de depósito internacional y los montos de las tasas para los Estados contratantes varían en función del número de diseños incluidos en la solicitud de depósito.

\section{Idiomas}

El Acta de 1934 prevé como único idioma de trabajo el francés, pero el Acta de 1960 establece que los depósitos internacionales y cualquier modificación a los mismos se registrarán y se publicarán en francés o en inglés. La correspondencia entre la Oficina Internacional y el depositante se hace 
en francés o en inglés, dependiendo del idioma usado por el depositante en su solicitud.

\section{Arreglo de Lisboa relativo a la Protección de las Denominaciones de Origen y su Registro Interna- cional}

\section{Introducción}

El Arreglo de Lisboa relativo a la Protección de las Denominaciones de Origen y su Registro Internacional se adoptó el 31 de octubre de 1958 y fue revisado en Estocolmo en 1967, y constituye un Arreglo particular entre los Estados miembros de la Unión de París ${ }^{21}$. Los Estados partes del Arreglo de Lisboa conforman la Unión de Lisboa.

Este Arreglo tiene especial relevancia a los efectos de proteger las denominaciones de origen por sí mismas, además de que brinda a los productos de esos países, que contengan una denominación, un valor agregado que impulsa las exportaciones $y$, por ende, el desarrollo de sus industrias.

\section{Objeto del Arreglo de Lisboa [artículos 1 y 2]}

Los Estados miembros de la Unión de Lisboa se obligan a proteger en sus territorios las denominaciones de origen de los productos de los demás países de la Unión reconocidas y protegidas como tales en el país de origen y registradas en la Oficina Internacional de la Organización Mundial de la Propiedad Intelectual (OMPI).

El Arreglo define la denominación de origen como una denominación geográfica de un país, de una región o de una localidad que sirve para designar un producto originario del mismo y cuya calidad o características se deben exclusiva o esencialmente al medio geográfico, comprendidos los factores naturales y los factores humanos. A estos efectos se entiende por país

${ }^{21}$ Actualmente hay 17 Estados partes del Arreglo de Lisboa, entre ellos los siguientes de América Latina: Cuba, Haití y México. 
de origen aquél cuyo nombre constıtuye la denominación de origen que ha dado al producto su notoriedad, o aquél en el cual está situada la región o localidad cuyo nombre constituye la denominación de origen que ha dado al producto dicha notoriedad.

\section{Contenido de la protección [artículo 3]}

La protección conferida por el registro internacional de las denominaciones de origen opera contra toda usurpación o imitación de la denominación protegida, incluso en los casos en que el verdadero origen del producto se indicara al usar la denominación de origen o si ésta se empleara como traducción o acompañada de expresiones desvinculantes o aclaratorias tales como «género», «tipo», «manera», «imitación», u otras similares.

La protección conferida por el Arreglo de Lisboa no excluye la protección que pudiera corresponder a las denominaciones de origen en cada uno de los Estados contratantes por virtud de otros instrumentos internacionales o por aplicación de la legislación nacional o de la jurisprudencia de los países vinculados.

\section{Registro internacional, denegación de protección[artículo 5]}

El registro de una denominación de origen se efectúa en la Oficina Internacional a pedido de la administración nacional competente del respectivo país miembro. El registro internacional se efectúa en nombre de las personas naturales o jurídicas, de derecho público o privado, que fuesen titulares del derecho de usar la denominación de origen de conformidad con la legislación nacional del país interesado. La denominación de origen debe ser reconocida y protegida como tal en virtud de la legislación interna del país de origen, en defecto de lo cual la denominación no puede registrarse en el registro internacional.

La Oficina Internacional procede a inscribir las denominaciones de origen y notifica los registros a las administraciones nacionales de todos los países miembros. Además anuncia los registros en el boletín Les appellations d'origine. 
Las administraciones nacionales que reciben la notificación pueden declarar, dentro del plazo de un año contado desde la recepción de la notificación del registro, que no pueden conceder la protección a la denominación de origen cuyo registro se les hubiese notificado. La declaración de denegación de protección no podrá perjudicar la protección que pudiera corresponder a la denominación de origen en el país de que se trate en función de otras normas aplicables conforme a la legislación nacional o a otros tratados a los cuales estuviese vinculado el país. Cuando se efectuara una declaración de denegación de protección dentro del plazo de un año previsto para el efecto, la Oficina Internacional la comunica a la administración nacional del país de origen. La persona o personas interesadas en la protección de la denominación de origen tendrán en el país que hubiese comunicado la denegación todos los recursos administrativos y judiciales que le corresponderían a los nacionales del país en circunstancias equivalentes.

\section{Conflicto con derechos anteriores de terceras personas [artículo 5(6)]}

Si una denominación de origen cuya protección fuese admitida en un país en virtud del registro internacional se hubiese estado usando por terceras personas en ese país desde una fecha anterior a la notificación del registro, por ejemplo a título de marca o de nombre comercial, la autoridad nacional competente podrá conceder al tercero afectado un plazo, que no podrá exceder de dos años, para que ponga fin al uso de la denominación de origen. Para estos efectos el país deberá informar de esta circunstancia a la Oficina Internacional, dentro de los tres meses siguientes a la expiración del plazo de un año previsto para la denegación de la protección.

\section{Denominaciones consideradas genéricas [artículo 6]}

Una denominación admitida para su protección en un país de la Unión de Lisboa no podrá considerarse que ha devenido en el nombre genérico o nombre común del producto al cual se aplica mientras la denominación se encuentre protegida como denominación de origen en el país de origen.

Esta disposición evita que se convalide un proceso de vulgarización o generalización de una denominación de origen en alguno de los países de la 
Unión de Lisboa. Estos países quedan obligados a reconocerle a las denominaciones de origen tal calidad y a darles protección mientras ellas continúen siendo reconocidas como tales en sus países de origen.

\section{Duración del registro a [artículo 7]}

El registro internacional de una denominación de origen asegura la protección de la denominación por un plazo indeterminado, sin necesidad de renovación. La protección derivada del registro internacional termina cuando la denominación de origen cesa de ser reconocida y protegida como tal en su país de origen.

\section{Acciones en defensa de una denominación de origen [artículo 8]}

Las acciones administrativas o judiciales necesarias para proteger las denominaciones de origen en los países de la Unión de Lisboa podrán ser ejercitadas a instancia de la administración nacional competente o del Ministerio Público, o por cualquier persona interesada, natural o jurídica de derecho público o privado. La legislación nacional de cada uno de los países determinará qué personas podrán ejercer las acciones referidas.

Ginebra, 28 de enero de 1993. 